\title{
LA EPIDERMIS DE LA ARQUITECTURA SANLUQUEÑA
}

\section{THE SKIN OF ARCHITECTURE SANLUQUEÑA}

\author{
FERNANDO CRUZ ISIDORO \\ Universidad de Sevilla. España \\ cruzisidoro@.us.es
}

\begin{abstract}
En este artículo se localiza y estudia un centenar de ejemplos de inmuebles de arquitectura doméstica, religiosa y militar con decoración externa de esgrafiados y policromía, que se hicieron en Sanlúcar de Barrameda durante los siglos XVII y XVIII. Sus fuentes de inspiración son identificadas y se establece catálogo de trabajo con los motivos conservados.

Palabras clave: Esgrafiados y policromía arquitectónica externa. Sanlúcar de Barrameda.
\end{abstract}

This article locates and studies a hundred examples of housings, religious and military buildings with externa decoration for sgraffito and polychromed, which were made in Sanlucar de Barrameda in the seventeenth and eighteenth centuries. His sources of inspiration are identified and a catalog is established with the conserved motifs

Keywords: the skin of architecture, externa decoration for sgraffito and polychromed, Sanlúcar de Barrameda.

Desde el mundo antiguo, en la arquitectura occidental, y hasta la época moderna, cuando el aparejo de una fábrica era considerado pobre o de escaso valor monumental o decorativo, ha sido habitual recurrir a recubrimientos que ocultasen esa carencia y a la par favoreciesen su conservación, al preservarlo de los agentes de erosión. En la arquitectura romana y, por inercia en la medieval y moderna que mantuvieron su influencia en mayor o menor medida, cuando se disponía del suficiente poder económico y de material, fue habitual el uso de placados marmóreos o pétreos, dependiendo de los recursos de la región (canteras o de acarreo), e incluso de mosaicos de materiales de alto valor, caso del arte románico, gótico y renacentista italiano. Pero cuando esos elementos escaseaban o eran pobres los caudales, no suelen faltar, ocultando las fábricas de ladrillo, tapial, mampostería e incluso de piedra, las imprescindibles capas a la cal, yeso o estuco que, tras recibir esgrafiados y policromía, igual imitaban labores de sillares 
o latericias, placados, o las más variadas y complejas tramas geométricas, emulando las alfombras de mosaicos de suntuosas solerías, alfarjes de madera, los sofitos de las viejas glorias del mundo clásico, difundidas por la tratadística italiana, o las más cercanas labores pictóricas o de yeserías del mundo musulmán y del estilo mudéjar. Sin olvidar, tampoco, las efectistas y vistosas figuraciones religiosas o mitológicas, dependiendo del carácter sacro o profano del inmueble.

Ese engaño visual y decorativo, propio de las tramoyas teatrales, que desea ocultar la pobreza de materiales o intenta la articulación de un paramento, cuenta en los últimos años con numerosas investigaciones, que no vienen al caso sintetizar, más desde finales de la década de 1980 para el ámbito geográfico que nos ocupa, cuando se empezaron a efectuar propuestas de restauración y divulgación de la arquitectura pintada andaluza, como en las I Jornadas de Conservación y Restauración de Bienes Culturales, celebradas en Cádiz en 1990 bajo el lema "El color en la arquitectura", repetidas en años posteriores ${ }^{1}$, y que tuvieron un fuerte revulsivo con la inyección económica de los proyectos de restauración acometidos en Sevilla para la Expo del 92, caso de la iglesia de Sta. María la Blanca ${ }^{2}$. Esa epidermis, a la escala apropiada, nos viene interesando desde hace más de una década en nuestro reiterado estudio de la arquitectura sanluqueña, por ciertas restauraciones que dejaron al descubierto retazos de esa piel, como en la parroquia de Ntra. Sra. de la O y en el baluarte de San Salvador ${ }^{3}$.

Unas primeras consideraciones ya las dimos a conocer en una conferencia celebrada en mayo de 2005 a instancias de la Asociación Cultural "Luis de Eguílaz" de Amigos del Libro y las Bibliotecas, que llevó por título "Sobre la ciudad ideal y la arquitectura dieciochesca del color: cuando Sanlúcar no era blanca”, donde

${ }^{1}$ Véase como obras generales: FERRER MORALES, Ascensión: La pintura mural: su soporte, conservación, restauración y las técnicas modernas. Sevilla, Universidad, 1995 y MALTESE, Conrado: Las técnicas artísticas, Madrid, Cátedra, 1990. O, a modo de ejemplo, FERRER MORALES, Ascensión: "Decoración de muros en castillos califales de Andalucía occidental”, Atrio, 8/9, 1996, pp. 3-18; CAMACHO MARTÍNEZ, Rosario: "Málaga pintada. La arquitectura barroca como soporte de una nueva imagen", ibídem. pp. 19-36; OLLERO LOBATO, Francisco: "Sobre el color en la arquitectura del arzobispado hispalense durante la segunda mitad del siglo XVIII", ibídem, pp. 53-75; BENITO ARTIGAS, Juan: "La piel del barroco", ibídem, pp. 77-87.

2 AGUILAR GUTIÉRREZ, Juan y ARENILlAS, Juan Antonio: "Las pinturas murales de la fachada de la iglesia de Santa María la Blanca de Sevilla y su restauración”, Atrio, 8/9, 1996, pp. 37-51.

${ }^{3}$ RODRÍGUEZ DUARTE, María del Carmen: "Hallazgos de pinturas y relieves en la iglesia de Ntra. Sra. de la O", Sanlúcar de Barrameda, 27, 1991, s./p.; "Hallazgos de pinturas góticas en la parroquia de Ntra. Sra. de la O de Sanlúcar de Barrameda", El Color en la Arquitectura, Cádiz, 1991. FERRER MORALES, Ascensión: "Decoración de los muros del fuerte de San Salvador. Sanlúcar de Barrameda (Cádiz)”, Sanlúcar de Barrameda, $31,1995, \mathrm{~s} / \mathrm{p}$. 
recogimos un catálogo inicial de edificios religiosos, civiles y militares y los temas representados, que devino en un artículo, de igual título, publicado ese verano en la revista Sanlúcar de Barrameda donde hacíamos relación de todos los inmuebles que mostraban esos elementos, algunos ya desaparecidos ${ }^{4}$. Ambas intervenciones tuvieron cierto eco en la ciudad, pues algunos dueños de viviendas empezaron a sacar esgrafiados y policromías de debajo de las múltiples capas de cal que los ocultaban, como marchamo de su antigüedad. Y esa línea de investigación tuvo proyección en varios discípulos, que presentaron ponencias en las I y II Jornadas de Investigación Sanluqueña, que venimos dirigiendo en la localidad, en mayo de 2011 y $2012^{5}$, e incluso esa temática formó parte sustancial del trabajo de investigación de uno de ellos ${ }^{6}$.

No obstante, en la labor de recuperación y divulgación en los medios audiovisuales, es de justicia dejar por escrito que la parte más importante la llevó a cabo, y sigue de forma incansable, el artesano sanluqueño don José María Sánchez $\mathrm{Muñoz}^{7}$, experto en labores decorativas y estuco que, con su incansable trabajo, ha sido quien personalmente ha sacado a la luz casi el cien por cien de todas las muestras de decoración de esgrafiados y policromías externas que se conservan en la ciudad, efectuando desinteresadamente labores de restauración y reintegración de los motivos, lo que le ha permitido sacar plantillas a escala real y reproducciones que han sido utilizadas en este artículo.

De ahí que el trabajo que ahora presentamos se sostenga, fundamentalmente, en la labor de campo, con la minuciosa inspección del caserío sanluqueño durante todo este tiempo, lo que nos ha permitido la identificación de los motivos decorativos (a veces no fáciles de ver) y su clara localización en el viario, estableciendo un catálogo con los conservados y perdidos durante este ciclo, que se podrá ampliar en un futuro, sistematizando las decoraciones, medidas, técnicas, y

${ }^{4}$ CRUZ ISIDORO, Fernando: "Sobre la ciudad ideal y la arquitectura dieciochesca del color: cuando Sanlúcar no era blanca”, Sanlúcar de Barrameda, 41, 2005, pp. 79-90. Ese artículo, muy abreviado, bajo el título "La mirada perdida del color", se difundió de forma masiva en Magazine cultural de Sanlúcar, n III, ese verano-otoño de 2005.

${ }^{5}$ POLO SERRANO, Carmen: "La epidermis de la arquitectura sanluqueña: esgrafiado y pintura mural exterior", Sanlúcar Señorial y Atlántica. I y II Jornadas de Patrimonio Histórico-Artístico 2011-2012, Sanlúcar de Barrameda, 2014, pp. 191-210; ALPRESA LEÓN, Manuel: "Artes aplicadas al muro, un arte singular", ibídem, pp. 221-244. No fue recogida en esta publicación, por su carácter práctico, la comunicación de José María Sánchez Muñoz titulada: "Sobre esgrafiados y pintura decorativa: técnicas y restauración", efectuada en esas Jornadas de 2011.

6 Trabajo de Licenciatura de Carmen Polo Serrano, titulado La epidermis del color en las fachadas barrocas andaluzas, defendido el 26 de septiembre de 2013, con la calificación de sobresaliente.

${ }^{7}$ CRUZ ISIDORO, Fernando: "José María Sánchez Muñoz "Pericache", un artesano sanluqueño”, Sanlúcar de Barrameda, 47, 2011, pp. 101-108. 
posibles fuentes de inspiración. Y es que, año tras año, a pesar de los lamentables menoscabos por desidia o ignorancia de los propietarios de los edificios y de los poderes públicos, que los pican y recubren con dañinas intrusiones de cemento hidráulico para no dejar siquiera testimonio de su existencia, nuevos ejemplos se nos vienen a la vista tras los periodos de lluvias, que dejan al descubierto las capas más internas de la corteza del caserío, fundamentalmente a una cierta altura, menos afectada por retoques, pues las gruesas capas de cal acumuladas durante años se craquelan y desprenden como las hojas en otoño y, en otras ocasiones, son los propios paramentos los que rechazan las modernas e intranspirables pinturas plásticas, por las diferentes tensiones que provocan.

Por ello, la Sanlúcar de época medieval y moderna, se nos antoja muy diferente de la actual, pues son ya más de un centenar los ejemplos recogidos de ficticias decoraciones en casas, bodegas y edificios religiosos y militares, lo que nos permite poder imaginar su aspecto cuando "no era blanca".

Para elaborar este trabajo, aparte de la labor de campo, se ha hecho difícil acudir a fuentes primarias distintas de los propios edificios, pues los censos, padrones y encuestas emitidos durante el siglo XVIII, momento álgido de esas decoraciones, no dan noticias al respecto, y tampoco los historiadores y cronistas coetáneos reflejan ese aspecto, quizás por obvio. Nada aparece en el texto redactado en marzo de 1752, a instancias de la Ciudad, por el regidor e historiador Juan Pedro Velázquez Gaztelu para las Respuestas Generales del Catastro de Ensenada, pero al menos nos informa como existían unas 1.800 casas $^{8}$. Y el mismo autor, en un manuscrito de julio de ese año, destaca la monumentalidad de sus casas: "por lo general, son de alegre aspecto, las más de ellas dobles con balcones y rejería de hierro, y algunas tan espaciosas, elegantes y bien labradas, que se duda, a excepción de Cádiz, las aya mejores en ninguna otra población del reino". Cabría esperar más en cuanto a la descripción de esas decoraciones, en sus manuscritos Fundaciones de todas las iglesias, conventos y ermitas e, Historia Antigua y Moderna de Sanlúcar, de hacia 1758 y 1760 respectivamente, que hoy en día son la piedra angular de la historiografía sanluqueña, donde para nada trata de los exteriores de edificios religiosos y públicos que, sin embargo, estudia concienzudamente. Se limita a señalar: "Las casas de los vecinos hacen justa correspondencia con los edificios públicos, pues son por lo general hermosas, alegres y esparcidas en lo interior y exterior, guardando las más, regular simetría en la correspondencia de puertas y ventanas, adornadas todas, de espaciosos balcones y rejerías de hierro; muchas pasarían por palacios en las cortes de los príncipes, y añadidos a esto

${ }^{8}$ SANLÚCAR DE BARRAMEDA 1752. SEGÚN LAS RESPUESTAS GENERALES DEL CATASTRO DE ENSENADA. Introd. de Jesús Campos Delgado y Concepción Camarero Bullón. Madrid, Tabapress, 1995, p. 240.

9 CRUZ ISIDORO, Fernando: "La Sanlúcar de 1752 según un texto de Juan Pedro Velázquez Gaztelu”, Sanlúcar de Barrameda, 47, 2011, pp. 42-51. 
la anchura y poca tortuosa rectitud de las calles, su regular aseo y comodidad de los empedrados, hacen nuestra Sanlúcar en concepto de cuantos la pisan, una de las más hermosas, alegres y risueñas ciudades de esta monarquía" ${ }^{10}$. Más interesante resulta un apunte sobre los aspectos técnicos del proceso de construcción de esas viviendas: "Para que estas fábricas fuesen siempre en mayor aumento, las ha fomentado el ayuntamiento con todas las facultades que le competen en esta parte, ya dando licencias de sacar y servirse de la piedra del puntal del Espiritu Santo, ya arreglando la calidad y tiempo de fabricar la cal, el yeso y ladrillo, señalándoles igualmente los precios a que deban vender o ya prescribiendo a los maniobreros los justos jornales que debían llevar por su trabajo. A cuyo beneficio conducía también la Ordenanza hecha el año de 1622 sobre la venta de vigas y tablas, y el cuidado de precaver las ruinas" ${ }^{11}$. Ratifica cómo las fábricas de la ciudad han sido históricamente de ladrillo y de mampostería mixta (ladrillo, tapia y piedra), reservándose la sillería para enmarque de vanos, lo que se comprueba con una simple inspección ocular y hemos documentado en cuanto a coste, procedencia y manipulación al hilo de los edificios estudiados. Debemos puntualizar que fueron dos las canteras básicas de extracción, pues la de la sierra de San Cristóbal, labrada con regularidad, se usó para la construcción de iglesias monumentales, como la del convento de Santo Domingo, y para elementos mimados como portadas y ventanas, bóvedas, impostas y cornisas, ángulos y ciertos detalles decorativos (castillo de Santiago, iglesias de la Caridad, Merced, Madre de Dios...), mientras que la piedra del puntal del Espíritu Santo, que es la que cita ese texto, más tosca por hostionera, sólo se empleó, por la baratura de su obtención, en obras civiles descuidadas, zócalos $\mathrm{y}$ vanos de casas de tipo popular pero con ciertas pretensiones, y para la arquitectura militar que exigiese bajo coste (castillo de San Salvador), pues en las casonas nobles se utilizó la de la cantera jerezana-portuense. De sus palabras se infiere el uso de forjados de madera, con alfajías para cubriciones planas y a un agua, cuyo simple tamaño determina el ancho de las cajas de muros de carga de las viviendas, muy uniforme en la localidad (unos cuatro metros y medio), y armaduras de progenie mudéjar, de par e hilera e incluso más complejas, al exterior tejadas, utilizando como materia prima el pino de Segura, viajero por el Guadalquivir hasta el muelle de Bonanza y, en ocasiones, el más afamado de Flandes, asequible en Sanlúcar por el excelso comercio de su puerto. Sin olvidar la cal y el yeso como materiales constructivos y de decoración.

Por el padrón de 1777, con motivo de marcar con azulejos numéricos las casas, comprobamos como seguían siendo 1.801 las viviendas, de ellas 710 en el Barrio Alto y 1.091 en el Barrio Bajo, cifra que se mantiene en los censos de Aranda,

${ }^{10}$ VELÁZQUEZ GAZTELU, Juan Pedro: Historia antigua y moderna de la muy noble y muy leal ciudad de Sanlúcar de Barrameda. Año de 1760, Vol. II, est. prelim. y transc. de Manuel Romero Tallafigo, pp. 398-399.

11 Ibídem, p. 399. 
de 1778, y de Floridablanca de 1787, que cifra en 14.844 los vecinos de la ciudad ${ }^{12}$. Tampoco comenta nada Antonio Ponz tras la visita que efectuó a finales de siglo, pues se limita a decir: "ha mejorado mucho de diez y siete o diez y ochos años a esta parte, que fue la primera vez que la vi, así en sus calles como en el caserío”, aunque ofrece un dato muy interesante, la reducción drástica de la población a 3.000 vecinos $^{13}$. El conde de Maule no aporta nada en su escrito de 1821; ni Pascual Madoz a mediados del XIX, sólo que sus calles eran anchas y alineadas, especialmente en el Barrio Bajo, que contaba con los "mejores edificios", y que la población era de 4.215 vecinos $^{14}$.

De las 1.800 casas censadas en el XVIII, se conservan, aproximadamente, la mitad, muchas reconstruidas o falseadas, con la sustitución de las cubiertas de madera tejada por azoteas, por lo que los más de 100 ejemplares estudiados representarían no el 6 , sino el $12 \%$ o más de las mismas. Hemos comprobado, que estas decoraciones se limitan al casco histórico reconocido, en el Barrio Alto, con puntos extremos en las calles Mesón del Duque, Sebastián Elcano y Sevilla, y en el Barrio Bajo, hasta las calles Plata, Banda Playa y Trasbolsa, pues hasta allí llegaba el arenal de la playa, hoy alejado.

Respecto a la consulta de fuentes documentales, que pudieran darnos datos fehacientes sobre el arranque, evolución y cronología local de estas decoraciones, autores y costes económicos, los resultados han sido hasta el momento prácticamente infructuosos. Pero hemos de aclarar, que la investigación en los archivos Municipal, Ducal y de otras instituciones de Sanlúcar, la hemos efectuado de forma secundaria a la realizada desde 1993 para documentar los edificios religiosos y militares sobre los que hemos escrito y, por tanto, aún admite una búsqueda de mayor profundidad. No obstante, contamos con algunas inscripciones, noticias documentales de artesanos y, por supuesto, con los trabajos de campo efectuados que nos permiten su datación.

En cuanto a fuentes visuales, los dibujos y grabados del caserío de la ciudad, escasos para la época que estudiamos (ss. XVI-XVIII), resultan decepcionantes. El del pintor flamenco Anton Van den Wyngaerde, más conocido como Antonio de las Viñas, sufragado por el VII duque de Medina Sidonia Don Alonso Pérez

12 SANLÚCAR DE BARRAMEDA 1752... op. cit., p. 84. DE LA CRUZ, Nicolás, conde de Maule: Viaje por El Puerto de Santa María a Sanlúcar de Barrameda. 1821, reimp. Sanlúcar, Bodegas Barbadillo, 1996, p. 19

${ }_{13}$ PONZ, Antonio: Viage de España, t. XVIII, Madrid, 1794, reed. Madrid, 1972, pp. 119-121.

${ }^{14}$ DE LA CRUZ, Nicolás, conde de Maule: Viaje por El Puerto de Santa María a Sanlúcar..., op. cit. MADOZ, Pascual: Diccionario geográfico-estadístico-histórico de España y sus posesiones de ultramar. Cádiz. Madrid, 1845-50, reimp. Cádiz, Ámbito ediciones, 1986, pp. 282-286. 
de Guzmán en $1567^{15}$, que resulta tan emblemático para la iconografía sanluqueña, pues nos permite conocer el urbanismo de esos momentos, cuando la ciudad crece, e incluso el aspecto de varios de sus inmuebles monumentales, obvia esas decoraciones, quizás por anteriores a su puesta de moda. E igualmente negativa resulta la representación de la ciudad, realizada por Francisco Díaz Pinto, en 1789, para el margen superior izquierdo del mapa topográfico que hizo del Coto de Doñana, pues se inspiró en la de Antonio de las Viñas ${ }^{16}$. Por el contrario, sí que resulta útil el plano de un sector de la ciudad que acompaña un pleito entre regidores sanluqueños, de 1715, pues se completa en la parte superior con un trozo de papel superpuesto y pegado con la representación de la parroquia de la O y el palacio de los Guzmanes, donde comprobamos como toda la fachada de esta casa, que mira a la barranca, de tapia y ladrillo, presentaba paramento imitando sillares a soga ${ }^{17}$.

Pasemos a su estudio. Lo primero será establecer una cronología aproximada de esta epidermis. Que sepamos, la pintura mural externa de carácter decorativa más antigua localizada hasta el momento es la mudéjar, de la primera mitad del XVI, que encontramos en la hornacina dispuesta entre el segundo arco, tapiado, y el tercero, ya practicable, de las antiguas Covachas, que son un conjunto de enmarques de piedra de las antigua doce tiendas de propiedad ducal llamadas en la documentación "de las sierpes", por la presencia de esos míticos seres marinos, de estilo hispano-flamenco y que recuerdan el manuelino, ubicadas en la Cuesta de Belén, en el muro de contención de los jardines del palacio de los Guzmanes, posiblemente mandadas realizar por el II duque don Enrique a finales de la década de $1470^{18}$. La pintura, de tipo vegetal, representa un conjunto de esquemáticas ramas de color almagra, que parecen un matorral, quizás el Árbol de la Vida que en la leyenda mesopotámica de Gilgamesh, buscó el héroe en el fondo del mar, entre monstruos marinos, como los que aquí se tallaron en piedra. Se completa con algunos semicírculos y su estado de conservación es pésimo.

Las segundas, con cierta seguridad de datación, principios del siglo XVII, en concreto posterior a 1604, son las figuraciones religiosas que Hernán Maldonado

${ }^{15}$ CRUZ ISIDORO, Fernando: "Antonio de las Viñas y los Pérez de Guzmán. Sobre la ejecución y pinturas de ciertos lugares de España en 1567: ¿las vistas de Tarifa, Zahara de los Atunes y Sanlúcar de Barrameda?" Archivo Español de Arte, LXXXVII, 346, 2014, pp. 163-170

${ }^{16}$ CRUZ ISIDORO, Fernando: "Un mapa topográfico del Coto de Doñana, de 1789, del arquitecto Francisco Díaz Pinto". Laboratorio de Arte, 17, 2004, pp. 501-508.

${ }^{17}$ Sobre este pleito y plano véase, RODRÍGUEZ DUARTE, María del Carmen: "La construcción del cabildo sanluqueño en la plaza de la Ribera y su problemática", Sanlúcar de Barrameda, 45, 2009, pp. 64-74.

18 CRUZ ISIDORO, Fernando: "Arte y Arquitectura en la Sanlúcar del Siglo XVI", Sanlúcar, la Puerta de América. Estudios históricos y artísticos, coord. y edic. de Fernando Cruz Isidoro, Sanlúcar de Barrameda, Fundación Puerta de América, 2012, p. 238. 
realizó en las hornacinas de la parte superior de la caña de la torre-campanario de la parroquia mayor de Ntra. Sra. de la O, descubiertas en la restauración de 1996, en tonos ocres y grisallas, de marcados perfiles y acusados volúmenes miguelangelescos para ser alcanzadas por la vista, dada su altura, donde se representan a San Pedro, San Pablo, San Lucas, San Félix de Valois y, posiblemente, a San Leandro ${ }^{19}$.

De 1626, es el recubrimiento exterior del baluarte de San Salvador de Bonanza, trazado por el arquitecto gaditano Jusepe Gómez de Mendoza, maestro mayor de las fortificaciones de Cádiz, en este caso al servicio del VIII duque de Medina Sidonia don Manuel Pérez de Guzmán para defender la desembocadura del Guadalquivir, obra mixta de cantería y albañilería que contrataron los albañiles Diego de Triana Ortiz y Francisco de Escalada. El muro, de mampostería de cantos de ripios y sillería hostionera extraída en Chipiona para ángulos, zapatas del arranque del parapeto, exterior de los merlones y garitas, se recubre con una gruesa capa o torta de cal para protegerlo de la humedad de la costa, que resulta imposible rayar una vez seca, como podemos constatar, con la que además se sellaron, formando una gruesa cinta, las uniones de los sillares, e incluso se recubrieron esos elementos, como atestiguan algunas zonas, empleándose para toda la obra 1.500 cahíces de cal, dado que es aglutinante básico en su aparejo mixto ${ }^{20}$. Aún se conservan paños de ese mortero, que debieron realizar los citados albañiles, que son testimonio de autoría, con un interesante ornamento de esgrafiados geométricos de círculos, triángulos de lados rectos o curvos al modo de enjutas entre piedras, juegos de círculos dentro de rombos y luego en cuadrados, sillares almohadillados sencillos de forma cuadrada con un doble esgrafiado, pirámides herrerianas (como los remates de la portada del atrio de Santo Domingo), o rellenos entre piedras, en las coqueras, que adoptan formas caprichosas, siempre con un esgrafiado de fuerte trazo ${ }^{21}$.

El resto de las decoraciones que vamos a estudiar podemos encuadrarlas, las menos, en la segunda mitad del siglo XVII, y el resto en el XVIII. De gran interés para datarlas resulta la que se conserva en la casa-palacio de los marqueses de Casa Arizón ${ }^{22}$, actualmente reconvertida en hotel tras su restauración y

19 Ibidem, pp. 292-293.

${ }^{20}$ CRUZ ISIDORO, Fernando: "Una defensa del Guadalquivir en su desembocadura: el castillo de San Salvador, en Bonanza", El emperador Carlos y su tiempo, Actas de las IX Jornadas Nacionales de Historia Militar, Sevilla: Cátedra General Castaños / Región Militar Sur, 1999, pp. 427-447.

${ }^{21}$ FERRER MORALES, Ascensión: "Decoración de los muros del fuerte de San Salvador..., op. cit., s/p.

${ }^{22}$ ANDALUCÍA AMERICANA. EDIFICIOS VINCULADOS CON EL DESCUBRIMIENTO Y LA CARRERA DE INDIAS. Sevilla, Consejería de Cultura de la Junta de Andalucía, 1989, pp. 255-257. 
remodelación, pues al presentar una superposición de motivos, en concreto en el paramento de la fachada de la calle Banda Playa, nos permite discernir una posible evolución en cuanto al uso de modelos, a lo que se añade el aliciente de incluir una fecha en su torre mirador, entre las ménsulas de su cornisa, " $A \tilde{N} O D E$ 1721 ", momento de construcción del inmueble, al que parece responder el revestimiento más interno de su dieciochesca decoración. De su estudio se infiere cómo los motivos de su capa más profunda y antigua resultan austeros y sencillos, al usar una simple imitación de sillares dispuestos a soga con tendel, siendo más ricos, por sus decorativos sillares almohadillados a soga trabados con listeles y calles que representan el tendel de mezcla, los que los cubren, jugando con la habitual bicromía ocre/blanco, que podrían responder al tercer cuarto del XVIII, cuando regentó la finca el II marqués y vizconde del Carrascal, Salvador Arizón, que heredó en 1755 y falleció en $1774^{23}$. Además, la decoración se completa, a la altura del cierre de un supuesto zócalo, con una cinta de meandro en S ligeramente tendida, donde se emplean hasta cuatro colores: blanco y ocre en el meandro para darle volumen, dorado en el círculo central y almagra en las enjutas. El esgrafiado resulta muy visible.

Esa interpretación estética en la evolución de los motivos parece refrendarla el conocimiento que tenemos de la cronología constructiva de varios edificios en los que aparecen. Por ejemplo los mismos sillares sencillos a soga, de masa de tono ocre y de tendel blanco, que decoran la fachada del convento de las carmelitas descalzas, en la calle de su nombre, que podemos fechar hacia 1675, momento en que para la consagración del templo se hizo una suntuosa fiesta ${ }^{24}$.

También resulta difícil fijar la época en la que estas epidermis dejaron de estar de moda y empezaron, poco a poco, a cubrirse de cal, hasta perder conciencia sus dueños y la sociedad de su existencia y valor, probablemente a lo largo del siglo XIX y definitivamente durante el XX. Una dinámica que quizás se aceleró por las sucesivas epidemias que asolaron Sanlúcar, al igual que otras ciudades andaluzas, en la primera mitad del ochocientos, que aconsejaron, como profilaxis sanitaria, el blanqueo de los paramentos con cal. Tenemos constancia documental de brotes de enfermedad, como el del mes de agosto de 1800 , de fiebre amarilla ${ }^{25}$ por el que perecieron 2.310 sanluqueños, un tanto por ciento muy elevado de la población

${ }^{23}$ VELÁZQUEZ GAZTELU, Juan Pedro: Catálogo de todas las personas ilustres y notables de esta ciudad de Sanlúcar de Barrameda. Desde la mayor antigüedad que se ha podido encontrar en lo escrito hasta este año de 1760. Estud. prelim., transcrip. y edic. de Fernando Cruz Isidoro. Sanlúcar de Barrameda, A.S.E.H.A, 1996, p. 84.

${ }^{24}$ VELÁZQUEZ GAZTELU, Juan Pedro: Fundaciones de todas las iglesias, conventos y ermitas de Sanlúcar de Barrameda. Año de 1758. Estud. prelim. y transcrip. de Manuel Romero Tallafigo. Sanlúcar de Barrameda, A.S.E.H.A., 1995, p. 478.

${ }^{25}$ CRUZ, Nicolás de la, conde de Maule: Viaje por El Puerto de Santa María a Sanlúcar..., op. cit., pp. 57-58. 
que podría ser el punto de inflexión, y que se reprodujo en 1804 y 1820, mientras que en 1833 y 1834 se padeció el cólera, procedente de Huelva, falleciendo 515 habitantes, que fueron 388 en el rebrote de 1854, que duró 75 días y motivó el auxilio de los infantes de Orleans, duques de Montpensier, que fundaron corte en la ciudad y dieron de limosna 10.000 reales, que se sumaron a los 42.653 de una suscripción popular, que sirvieron para adquirir medicinas y alimentar, durante ese periodo a 240 personas $^{26}$. Quizás fue el momento del cambio de imagen de la ciudad a la "Sanlúcar blanca" que ha perdurado hasta hoy.

En cuanto a la técnica de ejecución, se siguen las normas tradicionales, como dar tres capas de preparación ${ }^{27}$. La más interna y grosera formada por un cuarto de cal y tres de arena, una segunda o intermedia con un tercio de cal y dos de arena, y la externa, más fina, con iguales cantidades de cal y arena. Sobre ellas, los albañiles arañaban con grafios y compases de metal los perfiles de los motivos geométricos que, finalmente, rellenaban con policromía, que oscilaba de la bicromía ocre / blanco a la cuatricromía ocre / blanco / dorado / almagra ${ }^{28}$. Hasta el momento, sólo se han constatado dos casos en los que hay una cuarta capa, formada por un enlucido de estuco (dos partes de cal y una de polvo de mármol), en las casas de calle Ganado n ${ }^{\circ} 17$-esquina a Baños-y Caballeros n ${ }^{\circ}$ 9, conocida como Posada de Palacio.

Estas tramas decorativas, en la mayoría de los casos, se desarrollan sobre el conjunto de la fachada, en algunas ocasiones con motivos diferenciados por plantas, y en otras se reservan como orejetas para enmarcar vanos. Pueden formar pilastras de motivos para articular la superficie, generalmente áticos, en frisos que culminan fachadas, para rellenar huecos, o formando sillares de esquinas. Es interesante cómo se organizan sobre el paramento para salvar vanos, utilizando convencionalismos como listeles de terminación (Torno $\mathrm{n}^{\circ} 1$ ).

Pasemos a catalogar los motivos decorativos localizados.

a) Tramas que se extienden por toda la fachada:

\section{Reproducción de sillares}

Representa el mayor número de ejemplos conservados, lo que resulta lógico, ya que parece fue utilizada para ocultar las más baratas fábricas de ladrillo, tapia

${ }^{26}$ GUILlAMAS Y GALIANO, Fernando: Historia de Sanlúcar de Barrameda. Madrid, 1858, reimp. facs. Sanlúcar de Barrameda, A.S.E.H.A, 1990, pp. 262-264.

27 VITRUBIO, Marco Lucio: Los Diez Libros de Arquitectura, trad. de Agustín Blánquez. Barcelona, Iberia, 1997, Libro VII, cap. 3, pp. 176-178. Véase además, como obras esenciales. GARATE ROJAS, Ignacio: Arte de los Yesos. Yeserías y estucos. Madrid, Munilla-Leria, 1999; Arte de la cal. Madrid, Munilla-Leria, 1998.

28 ALPRESA LEÓN, Manuel: “Artes aplicadas al muro. Un arte singular”, Sanlúcar Señorial y Atlántica..., op. cit., pp. 221-241. 
o mixta del caserío sanluqueño, intentando emular las enriquecidas de piedra. Los modelos más cercanos los encontramos en edificios pétreos de la localidad, que muestran orgullosos sus paramentos de sillares, como la imponente fábrica del convento de Santo Domingo o en la fachada de las antiguas casas capitulares, o las cremalleras de sillares angulares de las torres del Homenaje y del Aula maior del castillo de Santiago y del baluarte de San Salvador. Además del ejemplo visual de portadas monumentales, como las del monasterio de Madre de Dios y del Santuario de la Caridad, o de elementos singulares, Covachas y pilastras de refuerzo del convento de la Merced.

Además de la contemplación de estas obras esparcidas por sus calles, los albañiles contaban con las fuentes literarias, ampliamente utilizadas, para la representación de los diferentes tipos de sillares y motivos geométricos que veremos a continuación. Hemos comprobado cómo se inspiraron, fundamentalmente, en Serlio, en concreto, en su Tercero y Quarto Libro de Architectura, edición traducida por Francisco de Villalpando y editada en Toledo en 1552 por Juan de Ayala.

Se distinguen varios subtipos del tipo de sillar representado:

\subsection{Sillares simples}

Generalmente dispuestos a soga (de cítara) y con forma bastante regular, pero no con absoluta precisión, se individualizan los sillares con un doble esgrafiado externo en paralelo, formando un listel relleno de tono más claro para contrastar con la pieza de tono oscuro. Las posibles fuentes de esa forma convencional de representación hay que buscarlas, junto a la forma de suturar con mortero los perímetros de sillares de algunas estructuras pétreas de la ciudad, como las pilastras del convento de la Merced, en los grabados de Serlio de su Tercer Libro, De las Antigüedades, en concreto los fols. XLIII y XLV, donde se observa un muro aparejado de esa manera; y en el del IV Libro, en cuyo fol. XVIII vto. recoge, en la creación de los sillares almohadillados del ornamento rústico, un primer estadio en su evolución.

Encontramos estas decoraciones de cronología más antigua, propias de la segunda mitad del XVII, en casas sencillas de una sola planta, como en Ángel $n^{\circ}$ 8; de dos como en Ángel $n^{\circ}$ 6, de patio claustrado en varios frentes que aún conserva una columna de mármol con capitel de castañuelas, síntoma de su cronología, y en Divina Pastora $n^{\circ} 13$; en viviendas seiscentistas de cierto porte y doble planta como la de Baños $n^{\circ} 3$, de interesante portada protobarroca de principios del XVII con orejetas y ancones, y en la desaparecida casa del Carril de San Diego $n^{\circ} 20$; en la de la calle Bolsa $n^{\circ}$ 63-65; en la planta baja de Caballeros $n^{\circ} 7$; en la hoy accesoria de Carmen Viejo $n^{\circ} 24$; en la buhardilla de Carmen Viejo ${ }^{\circ}$ 49; en Don Claudio n ${ }^{\circ} 14$; en las plantas bajas de Fariñas $n^{\circ} 13, n^{\circ} 33$ y n ${ }^{\circ} 42$; en el bajo y el alto de la desaparecida casa de Fariñas $n^{\circ} 66$ (sustituida por una construcción moderna que en nada guarda el estilo de las casas citadas); bajo la cornisa de Mar $n^{\circ}$ 26; en la planta superior de Mesón del Duque n 1-3; en Monteros 
$n^{\circ} 13-15$; en Parra n 15 ; Pirrado no 17 esquina a Rubiños 21; en la capa más profunda de la fachada de la Casa Arizón en Banda Playa; en la primera planta de Plata $n^{\circ} 33$; en Regina $n^{\circ}$ 6; en San Borondón $n^{\circ}$ 8; en la segunda planta de San Juan n ${ }^{\circ} 43-45$ (desaparecidos); en San Nicolás no 2; Santo Domingo ${ }^{\circ} 18$ esquina al Carril de San Diego; Sebastián Elcano n ${ }^{\circ} 44$; segunda planta de Torno ${ }^{\circ}$ 1; a soga y tizón en la planta baja de Trasbolsa $n^{\circ} 17$; Trascuesta $n^{\circ} 8$; decorando por entero las fachadas de la parroquia mayor de Ntra. Sra. de la O y del convento de las carmelitas descalzas en la calle de su nombre, incluso en los contrafuertes de obra y en la tapia de la calle Pozo Amarguillo; en la fachada del antiguo colegio de jesuitas en la calle Luis de Eguílaz n ${ }^{\circ} 14$; en el patio de la portería del convento de Regina Coeli; y en la fachada del Santuario de la Caridad por la calle Monte de Piedad. También los encontramos en la planta baja de casas principales, mientras que en la alta se desarrolla una decoración más rica, como en Caballeros $\mathrm{n}^{\circ} 9$ o Carmen Viejo n ${ }^{\circ} 58$; o se usa para reforzar visualmente ángulos, como en la Casa Terán, en Sto. Domingo n ${ }^{\circ}$ 80; en una casa derribada en Divina Pastora esquina a la Avenida V Centenario, de la que ha quedado en pie el ángulo con esta pintura; y en la desaparecida decoración de la casa de Albaicín esquina a Santiago.

\subsection{Sillares almohadillados sencillos}

De aspecto ligeramente enriquecido con respecto a los anteriores, y de cronología más moderna, pues resultan ya dieciochescos, como se comprueba en la superposición de Casa Arizón y por estudio de los inmuebles en los que aparecen, tienen como referente de obra los laterales de la tardomanierista portada de piedra del antiguo convento de Sto. Domingo, donde se observa una contraposición de los resaltes de las lisas caras de sillares almohadillados sobre los fondos en oscuridad. En el Tercer Libro de Serlio, esa tipología se muestra en el fol. IV vto. pero, sobre todo, en el citado grabado del fol. XVIII vto. del Quarto Libro, con la evolución del sillar almohadillado del aparejo rústico, en concreto los tres primeros sillares del dibujo segundo, que atiende a la descripción: "Después con alguna más delicadeza dividieron los quadros o sellares con una cuerda más honda que ellos, esto hazía con alguna más diligencia en quanto a labrar lo más polidamente...”.

Para lograr ese efecto en la epidermis sanluqueña, se marcan con dobles y concéntricas líneas paralelas la forma del sillar, relleno de ocre, y con esa misma forma de listel el tendel uniforme horizontal de cada hilada y la unión lateral y vertical de cada pieza, normalmente de tono claro, con lo que surgen tramas paralelas vinculadas por palos, creando un ritmo más decorativo que realista, pues parece flotar el sillar. Estos juegos de formas también recuerdan los alfarjes de artesones del renacimiento andaluz (Alcázar de Sevilla y Casa de Pilatos). De este modelo encontramos dos variantes en cuanto al rayado, la que al trazar los esgrafiados de los tendeles horizontales, por comodidad o descuido, los hace continuos incluso en el punto de unión con el rehundimiento vertical de los palos, como en calle Abades esquina a Pozo Amarguillo; Alcoba n ${ }^{\circ}$ 13; 
en la planta alta de Bolsa $n^{\circ} 65$ y en Bolsa $n^{\circ} 93$; en la planta superior de Caballeros $n^{\circ} 7$ y Carmen Viejo $n^{\circ} 41$, de interesante patio clasicista columnario de arcos rebajados; desaparecido en Carmen Viejo $n^{\circ} 43$; en el piso alto de Comisario $\mathrm{n}^{\circ} 1$ con separación superior de la cornisa con friso de almagra; en el alto de Cristo de las Aguas n 10; en los pisos superiores de Mesón del Duque n 1012 y en Monte de Piedad n ${ }^{\circ} 11$, totalmente restaurado; en ambas plantas de Misericordia $n^{\circ} 9$ esquina a Trillo; en la casa desaparecida de San Nicolás n ${ }^{\circ} 14$, de la que subsiste un trozo de muro, cargando sobre la casa contigua, con esta decoración; Santo Domingo ${ }^{\circ}$ 37; y en Truco s/n., donde incluso se despliega por una pilastra.

Y la que interrumpe el rayado en ese punto, como en la planta baja de la casa de calle Baños $n^{\circ} 13-15$; planta $2^{a}$ de la casa de Benegil $n^{\circ} 2$; en el zócalo de la torre de la Puerta de Jerez; o en las ya desaparecidas decoraciones del piso bajo de Fariñas $n^{\circ} 43$ que tuvimos ocasión de fotografiar al caerse una farola y dejar ese trozo del muro al aire, y de la planta superior de Fariñas $n^{\circ} 45$; Santiago $n^{\circ} 24$; planta superior de las casas de Santo Domingo $n^{\circ} 7, n^{\circ} 8 y^{\circ} 56$, esquina a Siete Revueltas.

En ocasiones, los restos visibles son tan escasos, que resulta difícil observar por completo la seriación de varios de estos sillares, como en el piso superior de Cristóbal Colón esquina a Regina $n^{\circ} 19$; en la planta superior de Fariñas13, de interesante portada barroca de recerco entre pilastras toscanas y balcón superior; en Fariñas n ${ }^{\circ} 15, n^{\circ} 20$ y n ${ }^{\circ} 33$; en el sillar esquinero de Pozo Amarguillo no 63; en el colegio de la Caridad, antiguo convento de San Agustín, en la calle San Agustín $n^{\circ} 5$; en Santo Domingo $n^{\circ} 49$; Ganado $n^{\circ} 48$; en la planta segunda de Torno $\mathrm{n}^{\mathrm{o}} 22$ y en Trasbolsa $\mathrm{n}^{\circ} 15 \mathrm{y} \mathrm{n}^{\circ} 17$.

\subsection{Sillares almohadillados en punta de diamante "de tabla llana"}

Siguiendo el esquema básico de representación anterior, se añade parte del aspecto de la punta de diamante, pero truncándola con una tabla llana, como lo denomina Serlio y representa, de nuevo, en el grabado del fol. XVIII vto. del Quarto Libro con la evolución del sillar almohadillado del aparejo rústico, en concreto en el tercer dibujo. Se caracteriza, por tanto, por la presencia de esa placa rectangular al centro. Otra posible fuente de inspiración serían los diseños de puertas casetonadas, como las del Quarto Libro, Orden Compuesto, a los fols. LXX y LXXI e, incluso, de alguna antigua puerta de la localidad (Comisario $\mathrm{n}^{\circ} 1$ ). Los vemos en las segundas plantas de la mercantil casa de Bretones n ${ }^{\circ} 28-30$; de Carmen Viejo $\mathrm{n}^{\circ}$ 58; en la capa más moderna de la Casa Arizón a Banda Playa; en Ganado $n^{\circ} 10$ esquina a Baños, de torreón angular; en Santo Domingo ${ }^{\circ} 44$, esquina a Don Claudio; en Fariñas $n^{\circ} 42$; en el piso superior de Plata $n^{\circ} 33$; en el convento de las Hermanas de la Cruz, en la plaza de Santa Ángela $n^{\circ}$ 3, de interesante portada dieciochesca con balcón superior, de recerco mixtilíneo plegado sobre el dintel como una dúctil cinta, cruz sobre Gólgota en la clave y pilastras 
cajeadas, y en la fachada a la calle del Ángel; y en la casa de Santo Domingo $\mathrm{n}^{\mathrm{o}}$ 44 esquina a Don Claudio. En otras ocasiones nos consta su desaparición, como en la planta baja de Fariñas n ${ }^{\circ} 43$; y en la segunda de San Jorge n ${ }^{\circ} 18$.

\subsection{Sillares almohadillados en punta de diamante}

Representan la tipología de sillar más compleja utilizada en Sanlúcar, dispuestos a soga y tizón, como vemos en la fachada del palacio de la Condesa de Lebrija, en la plaza del Pradillo o de la Salle $n^{\circ} 1$, reproduciendo exactamente el diseño serliano del ya tantas veces citado grabado, en concreto el dibujo cuarto.

\section{Formas geométricas}

Representan las decoraciones más vistosas por la complejidad e individualidad de sus motivos, que se repiten seriadamente formando tramas por toda la fachada, tanto en viviendas populares, de una sola planta y en lugares antaño próximos al mar, como en las de mayor porte de dos plantas y céntrica ubicación, conservándose en menor número.

Sus antecedentes históricos arrancan con los pavimentos de alfombras de mosaicos romanos de opus sectile y tesellatum y, posteriormente, con las tramas geométricas de los zócalos de azulejería y recubrimientos de yeserías musulmanas, o los paños de sebka almohades, como los de la Giralda, que tanta repercusión tuvieron en las artes decorativas mudéjares de alicatados, yeserías, pinturas murales y redes decorativas en piedras, como las pinturas del monasterio de San Isidoro del Campo en Sevilla, vinculado a los Guzmanes, y las del castillo de Luna en Rota, con tramas de lacerías de estrellas y polígonos o, más cercanamente, la pétrea decoración de la portada de los pies de la parroquial de la O. A lo que añadir las tramas geométricas clasicistas desarrolladas en alfarjes y cubiertas, como la serliana de la sacristía del Santuario de Ntra. Sra. de la Caridad, con juegos de hexágonos y triángulos.

Tampoco hemos de olvidar, por la vinculación comercial de Sanlúcar con el Mediterráneo oriental, el conocimiento de las complejas labores de embutidos de mármol y piedras diversas de los pavimentos italianos y otros elementos, como columnas entorchadas y objetos litúrgicos, que difundieron familias de artesanos como los Mellini, Cosma o Vasaletto. Y, por supuesto, la vía literaria, de tan amplia difusión, y de nuevo el Quarto Libro de Serlio ofrece un buen elenco de grabados, dentro del orden compuesto, con diversas variaciones de artesones y tramas, en los fols. LXXIII vto., LXXIIII vto, LXXV y vto., LXXVI vto. y LXXVII.

Veamos los motivos localizados:

\subsection{Red de lacería de a ocho.}

Encontramos esta forma mudéjar de progenie musulmana tres veces. En Ancha esquina a Isaac Peral, sobre los viejos soportales de un conjunto de casas que arrancan en la segunda mitad del siglo XVI, reformadas hasta la actualidad, pero 
que aún conservan sus soportes columnarios originales embutidos en el muro; en la calle Plata $n^{\circ} 15$, desarrollada sobre una estrella octogonal blanca de interior circular de almagra y fondo ocre, con el esgrafiado muy marcado.

\subsection{Red de encintado angular formando rombos.}

Alternando la almagra y el ocre, con las cintas blancas, se alcanza un alto nivel decorativo en los paños verticales de la planta $2^{\circ}$ de la casa principal "Posada de Palacio" de Caballeros n ${ }^{\circ}$ 9, que conserva un amplio surtido de elementos decorativos, esencialmente en su planta superior, restaurados en 1986 por don José María Sánchez Muñoz, verdadero escaparate, por su lugar de ubicación, en la divulgación y conservación de esta decoración epidérmica.

\subsection{Red de ángulos en V contrapuestos}

Formando paños en cinta horizontal, se utilizan para encerrar superiormente los paños anteriores en la casa de Caballeros $n^{\circ}$ 9, usando los mismos tonos.

2.4. Red de octógonos cargados con estrellas de ocho puntas enlazados por figuras pentagonales.

Recordando el dibujo $4^{\circ}$ de la lám. LXXIIII vta. de la Orden compuesta del Quarto Libro de Serlio, se extiende por la planta superior de la casa de Plaza de Madre de Dios $n^{\circ} 9$.

\subsection{Red de alizares y losetas cuadradas y rectangulares.}

Jugando con paralelas líneas diagonales que se cruzan, se crea una trama de losas mayores y menores, usando como articulador hiladas de aisladas losetas mayores cuadradas. La encontramos en la casa de una sola planta de la calle Ángel $n^{\circ} 8$, en la fachada que mira a Trasbolsa. Recuerda en algo la lám. LII del Tercero Libro de Serlio, donde explica el aparejo de las termas romanas de Diocleciano.

\subsection{Damero de líneas horizontales y pequeñas cajas en losange.}

En la casa de cargadores a Indias de la familia Barbadillo, en Santo Domingo $n^{\circ} 38$ esquina a Don Claudio, de pétrea portada barroca entre semicolumnas elevadas sobre altos pedestales, de fuste con faja de cinta vegetal, y recerco mixtilíneo con motivos de rocallas vegetales.

2.7. Red de cajas cuadradas y rectangulares enlazadas por pequeñas peltas.

Recientemente se ha restaurado un paño con 16 cajas en la planta superior de la casa $n^{\circ} 43$ de la calle Fariñas, donde se juega con la bicromía de listeles en blanco e interiores ocres. 
2.8. Red de cajas cuadradas enlazadas por pequeños cuadrados.

De bordes formados por un listel de doble línea, aparece en la planta superior de las casas principales de Ganado $\mathrm{n}^{\circ} 10$ esquina a San Miguel, de hermosa portada barroca de orejeta y flanqueo de pilastras, soportando dentículos un balcón de hierro. Recuerda la trama anterior.

2.9. Red de cajas achaflanadas entre círculos de dos tamaños.

Jugando con círculos de dos tamaños rellenos con puntos alargados en almagra, aparece en la planta superior de Sebastián Elcano n 36-38.

2.10. Red de listeles a la que se sobrepone una gruesa malla aspada.

En calle Plata ${ }^{\circ} 26$.

2.11. Malla de eslabones de óvalos verticales.

Reproduce el dibujo $1^{\circ}$ de la lám. XIII vta. del Tercero Libro de Serlio, donde representa ornamentos pétreos del templo romano de Baco. Como si se tratara de una cota de armas de hierro, se suceden los hilos de metal trenzando entre sí óvalos y círculos. La encontramos en el piso superior de Baños $\mathrm{n}^{\circ}$ 13-15 esquina a Ganado, sobre un planta baja con imitación de sillares almohadillados sencillos. Como enmarques inferior y superior se utiliza una cinta en almagra.

2.12. Círculos tangentes ente listeles horizontales.

En la planta superior de la casa de Don Claudio $n^{\circ} 15$ esquina a Fariñas $\mathrm{n}^{\circ} 32$. Forman dobles líneas de esgrafiados.

\subsection{Cuadrilóbulo inscrito en un cuadrado.}

Recuerda el dibujo cuarto de la lám. LXXV y el 21 de la lám. LXXVI vta. del Orden compuesto del Quarto Libro de Serlio.

* Con estrella central de ocho puntas.

Lo vemos en la planta $3^{\text {a }}$ de la casa principal de la calle Benegil $n^{\circ} 2$; y ha desaparecido, hace muy pocos años, de la de Ancha $n^{\circ} 42$ esquina a Cervantes, que tenía policromado en ocre el motivo y en almagra la estrella.

*Entre eslabones lobulados

En la segunda planta de la casa de San Juan n ${ }^{\circ}$ 60; y en el ático de Santiago n ${ }^{\circ} 24$.

\subsection{Múltiples motivos y formas caprichosas al azar}

Círculos, triángulos de lados rectos y curvos, juegos complejos de círculos en el interior de rombos y luego en cuadrados, sillares almohadillados sencillos de forma cuadrada, pirámides como las usadas en edificios herrerianos y formas caprichosas que surgen en las coqueras o intersticios entre piedras, en el baluarte de San Salvador, realizados en 1627. 


\subsection{Formas no identificadas}

- ¿Encintado en aspas con centros en círculos?

Apenas visible por las capas de pintura, se advierte parte de este motivo inmediato al puntal de apeo de hierro dispuesto a la izquierda de la portada de la casa principal de los Gutiérrez Nudi de la calle Barrameda n ${ }^{\circ}$ 2, de la que sólo se conserva la fachada. -¿Aspas?

En la planta segunda de Torno $\mathrm{n}^{\circ} 8$. -¿Motivos estrellados con círculo central?

Apenas se advierten, entre simuladas pilastras, en la planta $3^{\mathrm{a}}$, de Bretones $\mathrm{n}^{\circ} 24$.

b) Motivos de articulación del espacio.

\section{Pilastras de cajas.}

Con perfilados en almagra, calles en blanco y cajas centrales en ocre, como elemento articulador, encajándose entre la imposta y la cornisa superior de la tercera planta de la casa principal de mercaderes, de origen seiscentista y reformas dieciochescas, de Bretones ${ }^{\circ} 24$.

2. Pilastras de rectángulos de lados menores curvos entrelazados.

Eslabones en alternancia de ocre y almagra, con interiores de rombo centrado por círculo o de elipse con losange interior, alternando ambas policromías, las encontramos articulando el piso superior de la casa de Caballeros $n^{\circ} 9$.

\section{Pilastras con ferronerías}

Recuerdan labores de ferronerías y parecen reproducir las de la lám. LXVI del Orden compuesto del Quarto Libro de Serlio. Se encontraban en el ático de la casa de San Agustín n ${ }^{\circ}$ 14-18, desaparecidas tras la reciente restauración del inmueble. La labor de ferronería se policroma en ocre, los enmarques de listel en almagra y los fondos eran blancos.

Variante de la anterior, las encontramos, restauradas, en el ático de la casa $\mathrm{n}^{\circ}$ 19 de Regina esquina a Cristóbal Colón.

\section{Pilastra con eslabones entrelazados dobles.}

Repitiendo el dibujo $3^{\circ}$ de la lám. LXXVI del Orden compuesto del Quarto Libro de Serlio, la encontramos en el fuste de las pilastras toscanas de la capilla abierta del Cristo de las Aguas, esquinera en chaflán, entre la calle de ese nombre y Santiago. Utiliza la almagra como fondo, interiores claros, centros circulares en azul, y doble esgrafiado.

\section{Orejera de doble cinta.}

Jugando con la bicromía de ocre y almagra, enmarca el balcón principal de la planta segunda de la casa noble de Caballeros $n^{\circ}$ 9, que presenta en la clave una 
cruz de malta de brazos flordelisados ocre sobre almagra; y en los balcones del tercer piso de Santiago ${ }^{\circ} 24$.

\section{Orejera ancha.}

Enmarcando el vano de la torre de la Puerta de Jerez; y los balcones del ático o tercera planta de la casa de San Agustín n 14-18, desaparecida.

\section{Orejera fina.}

Enmarca los ojos de buey abocinados del piso superior de Monte de Piedad $\mathrm{n}^{\mathrm{o}} 11$.

\section{Friso con eslabones entrelazados sencillos.}

Repitiendo el dibujo $4^{\circ}$ de la lám. LXXVI del Orden compuesto del Quarto Libro de Serlio, lo encontramos en la capilla abierta del Cristo de las Aguas, entre la calle de ese nombre y Santiago; en el friso bajo la cornisa de la Casa Arizón a calle Divina Pastora, desaparecido hace poco, así como por debajo del ático serliano, que se conserva parcialmente en la fachada al callejón de Arizón; y bajo la cornisa del $n^{\circ} 15$ de la calle Plata

\section{Friso con $S$ tendidas.}

Lo encontramos, restaurado, en el ático de la casa de Regina $\mathrm{n}^{\circ} 19$ esquina a Cristóbal Colón.

\section{Friso de ondas en $S$ tendida.}

Reproduce el esquema del friso de la lám. LXXIII del Tercero Libro y las ondas de la lám. LXXVI del Quarto Libro de Serlio. Lo encontramos como elemento separador del zócalo y el paño superior de sillares almohadillados de la fachada a Banda Playa de la Casa Arizón. Utiliza almagra para los fondos, ocre para los círculos, y tono claro para las $\mathrm{S}$.

\section{Friso en doble cinta de entrelazos curvos.}

Elemento horizontal que cierra, finalmente, la decoración de la planta superior, de la citada casa de Caballeros $n^{\circ}$, repitiendo policromía.

12. Friso con losanges con flores de cuatro pétalos en alternancia con figuras de pájaros.

Aparecía cerrando el panel de decoración de sillares almohadillados de la casa de Santo Domingo ${ }^{\circ} 56$ en la fachada que da a la calle Siete Revueltas, lamentablemente desaparecida, pero de la que subsiste testimonio fotográfico. 
13. Formas no claras.

-Listel con doble línea de esgrafiado para enmarcar los balcones de la tercera planta de la casa $n^{\circ} 2$ de Benegil.

-Listel doble enmarcando formas

En el piñón de la pila de refuerzo de una bodega de la calle Cristo de las Aguas a Cruz del Pasaje.

- Arcos de medio punto esgrafiados, formados por dos listeles concéntricos. Enmarcan el balcón derecho de la casa nº 16 de Ancha.

Fecha de recepción: 30 de septiembre de 2015.

Fecha de aceptación: 20 de noviembre de 2015. 


\section{DEL ORNAMENTO RVSTICO.}

Las primeras obras rufticas fueron hechas de efta manera de pieças o fellares de piedra grueffamente defboçado, como a punta de pico que aca llamamos:mas avnque lo hazian grueflamente labrado: para q̨las juntas fucffen fubtiles y delıcadas, auia muy gran auifo y diligencia.

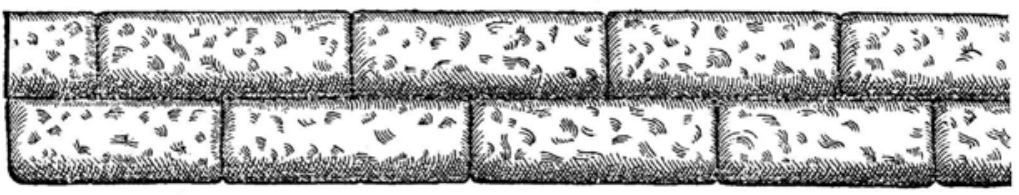

Defpues con alguna mas delicadeza diuidicrŏ los quadroso fellares cóv vna cuerda mas hóda ọ ellos, efto haziă cō algữa mas diligëcia en quăto a labrar los mas polidaméte, $y$ defpues fobre efto le acrecẽ tarổ açllla manera. de cruzes por arifta, para dalles masornamento.

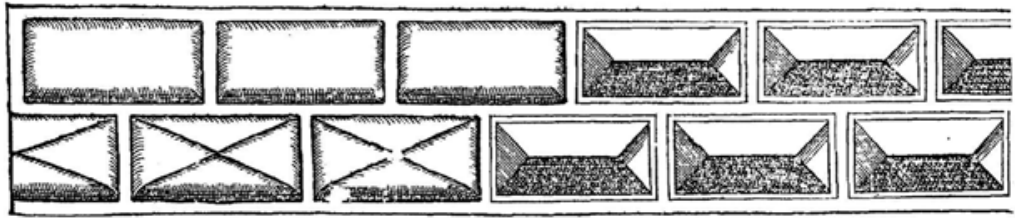

Todas las cofas han venido de hedad en hedad mudandofe de muchas maneras, cn algunas de cllas acrecentando, y en otras difminuyendo. Efto digo, porque algunas vezes han hecho algunas fellarerias de forma de diamantes de tabla llanos, y otras vezes con mas relieuo, affi como fe vee aqui abaxo.

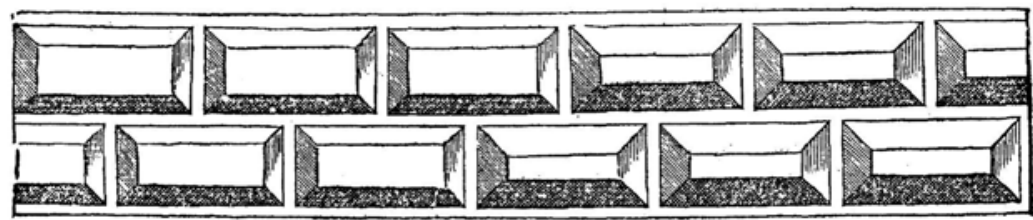

Algunos otros architcetos han labrado mas polido, y de mas ordenado cópartimiêto deftas mancras de fe liarerias:pero por muy delicaclas que fe hagan, no puedé dexar de tener eftas tales obras origé de la forma ruftica:avnque comunm nnte fe llitna efta fellareria Punta de diamante.

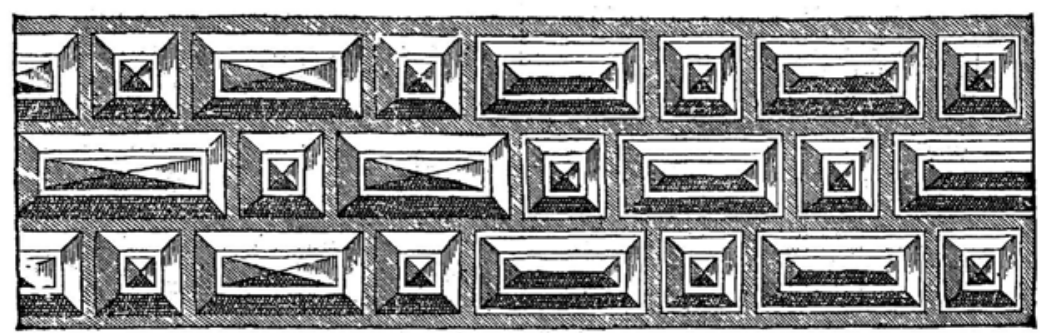

\section{AQVI FENECEN I.AS ORDENES TOSCANA Y RVSTICA Y COMIENCCA LA DORICA.}

Figura 1. Motivos de sillares. Serlio, Tercero y Quarto Libro de Architectura, trad. de Francisco de Villalpando, Toledo, Juan de Ayala, 1552, fol. XVIII vto. 


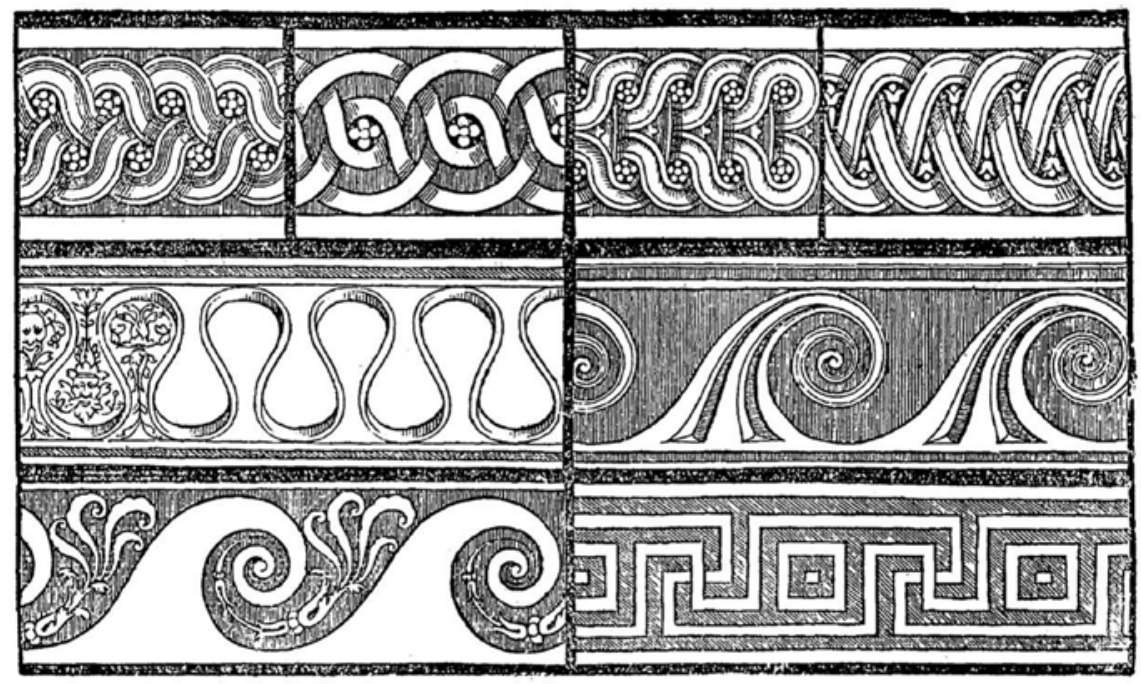

Figura 2. Motivos geométricos de entrelazos, eslabones, cintas, ondas y meandros. Ibídem fol. LXXVI.

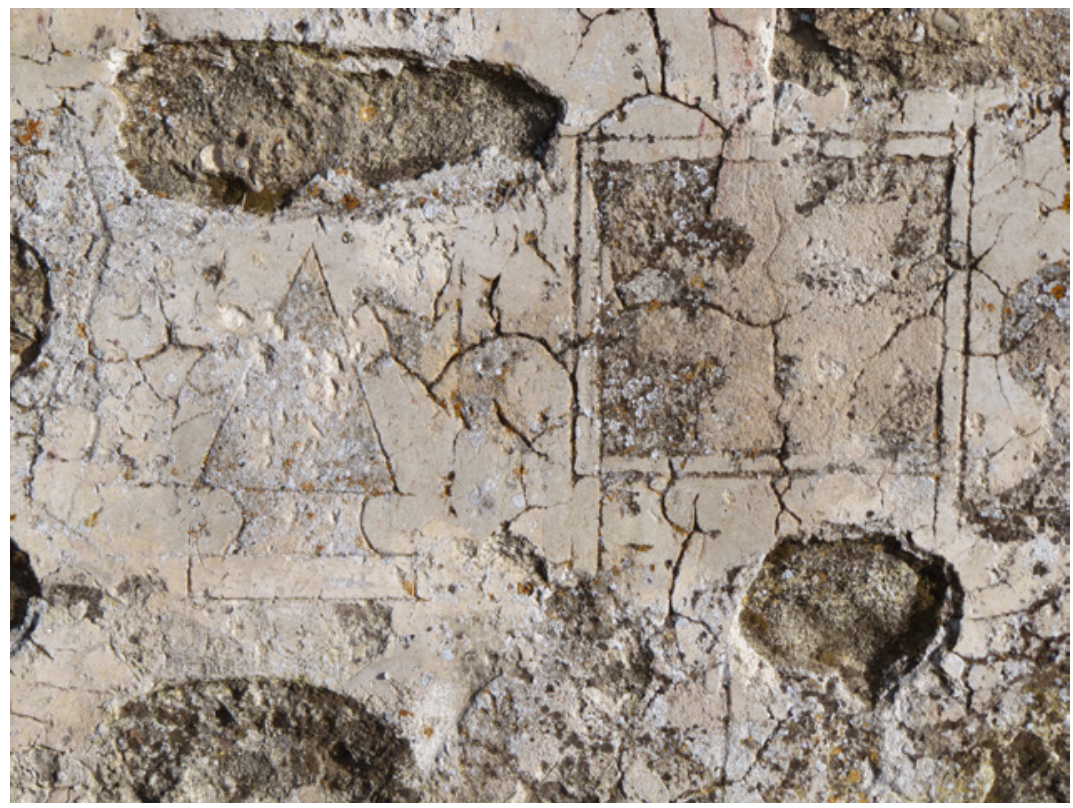

Figura 3. Baluarte de San Salvador de Bonanza. Esgrafiados de Diego de Triana Ortiz y Francisco de Escalada, 1626. 


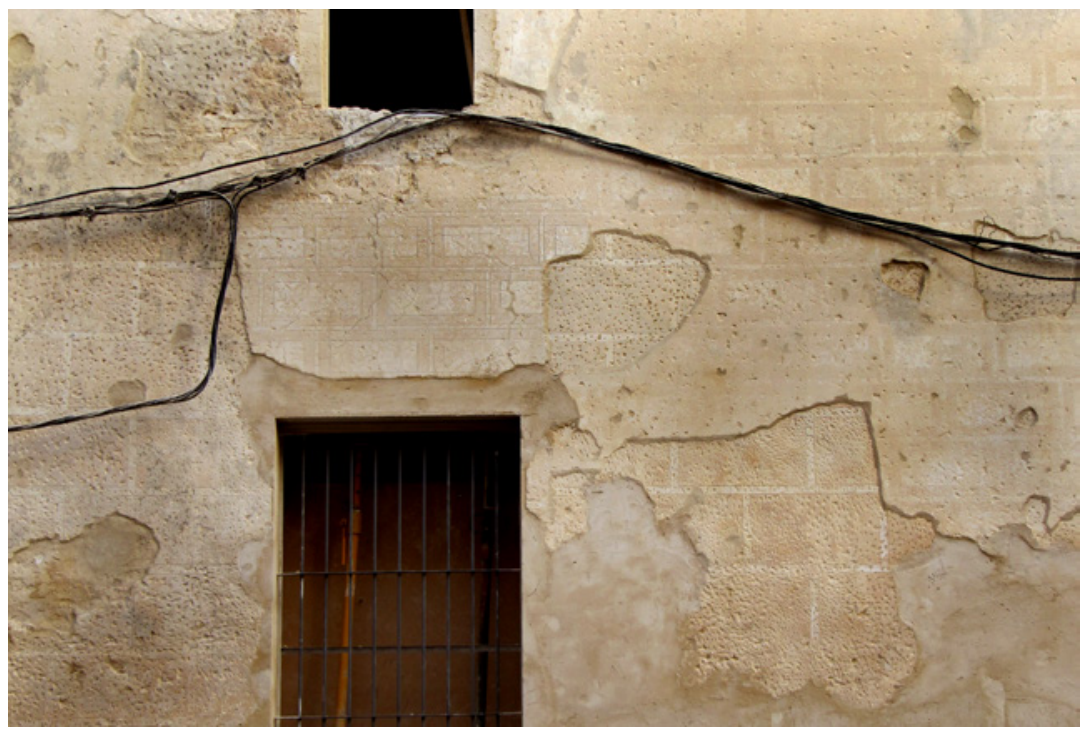

Figura 4. Casa de los marqueses de Arizón. Calle Banda Playa. Superposición de sillares simples y almohadillados. 1712 y posterior.

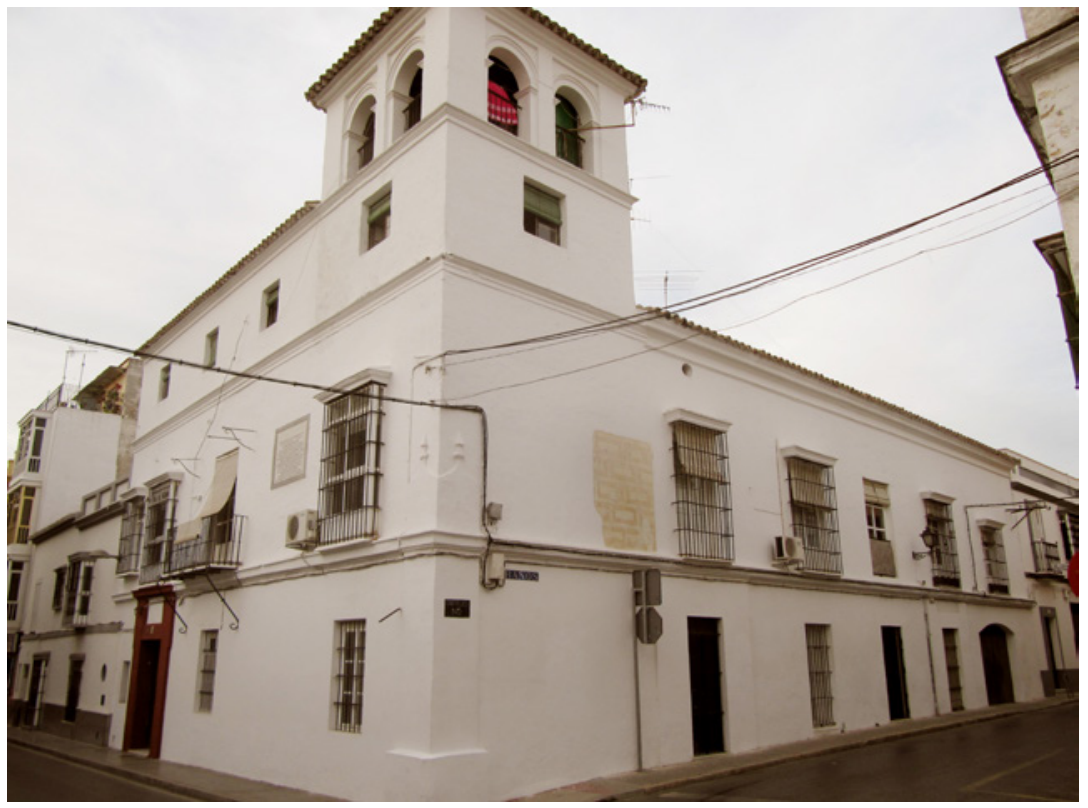

Figura 5. Casa en c/ Ganado ${ }^{\circ} 10$ esquina a Baños. Sillares almohadillados en punta de diamante "de tabla llana". 


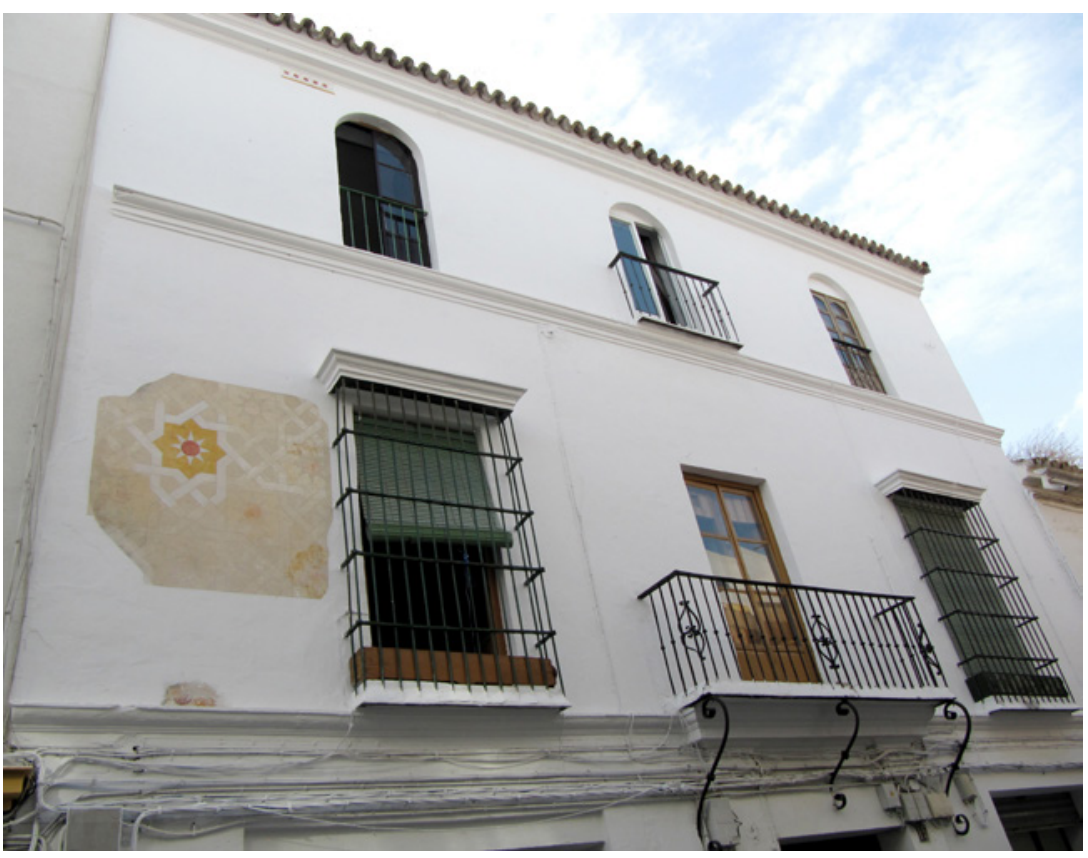

Figura 6. Casa en c/ Plata ${ }^{\circ} 1$. Red de lacería de a ocho.

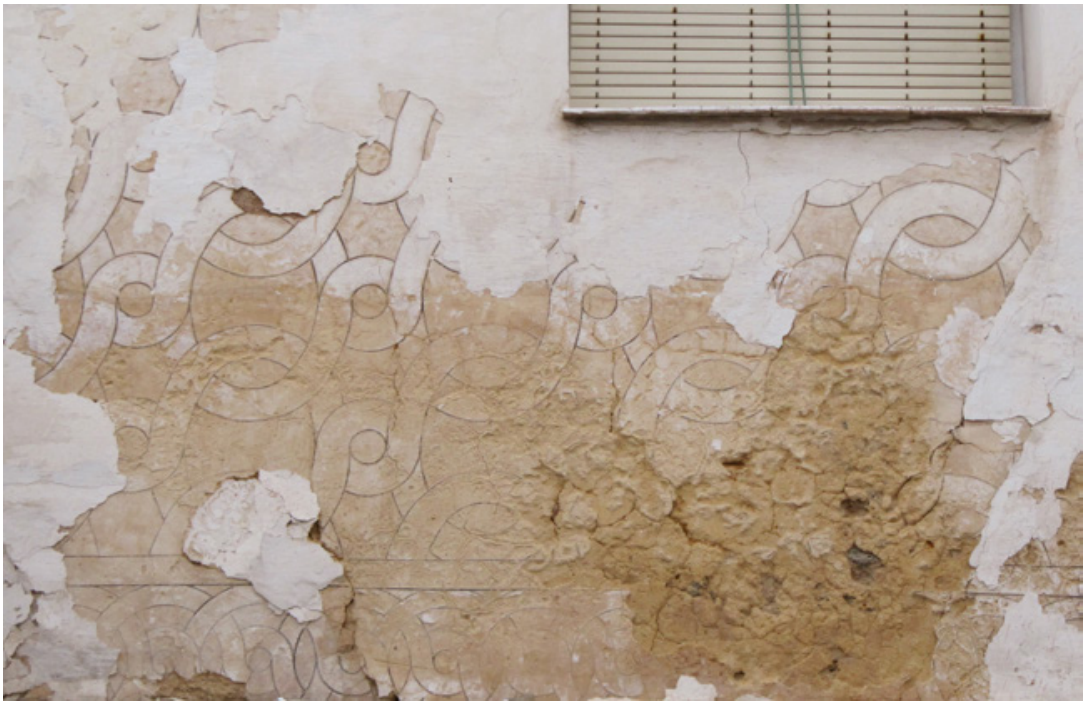

Figura 7. Casa en c/ Baños no 13-15 esquina a Ganado. Malla de eslabones de óvalos verticales. 


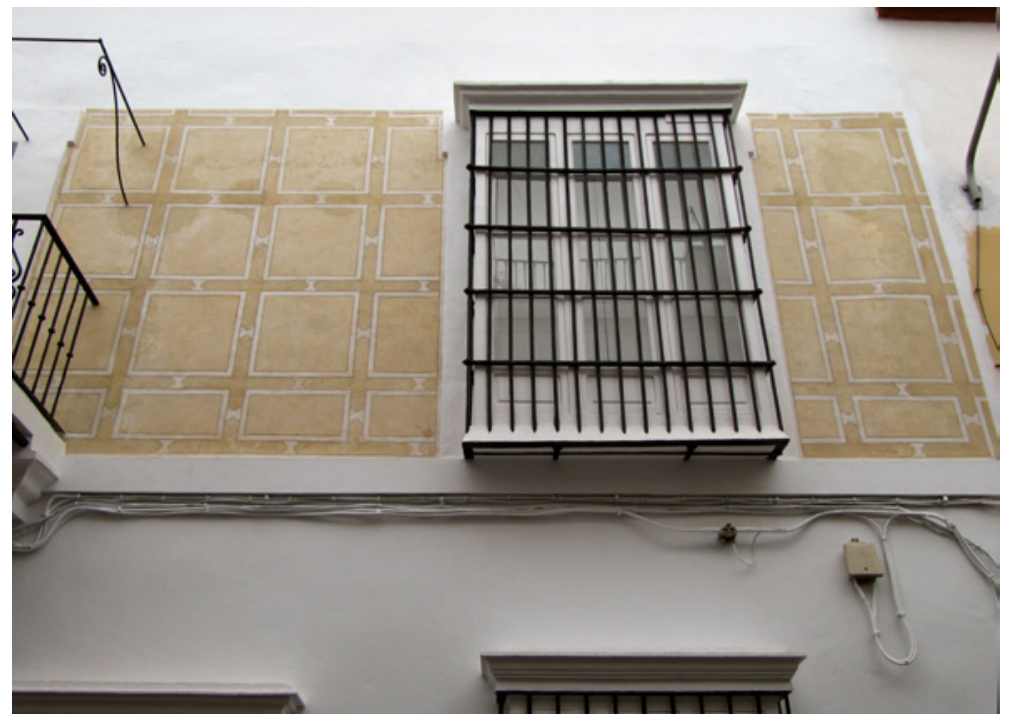

Figura 8. Casa en c/ Fariñas n ${ }^{\circ}$ 43. Red de cajas cuadradas y rectangulares enlazadas por pequeñas peltas.

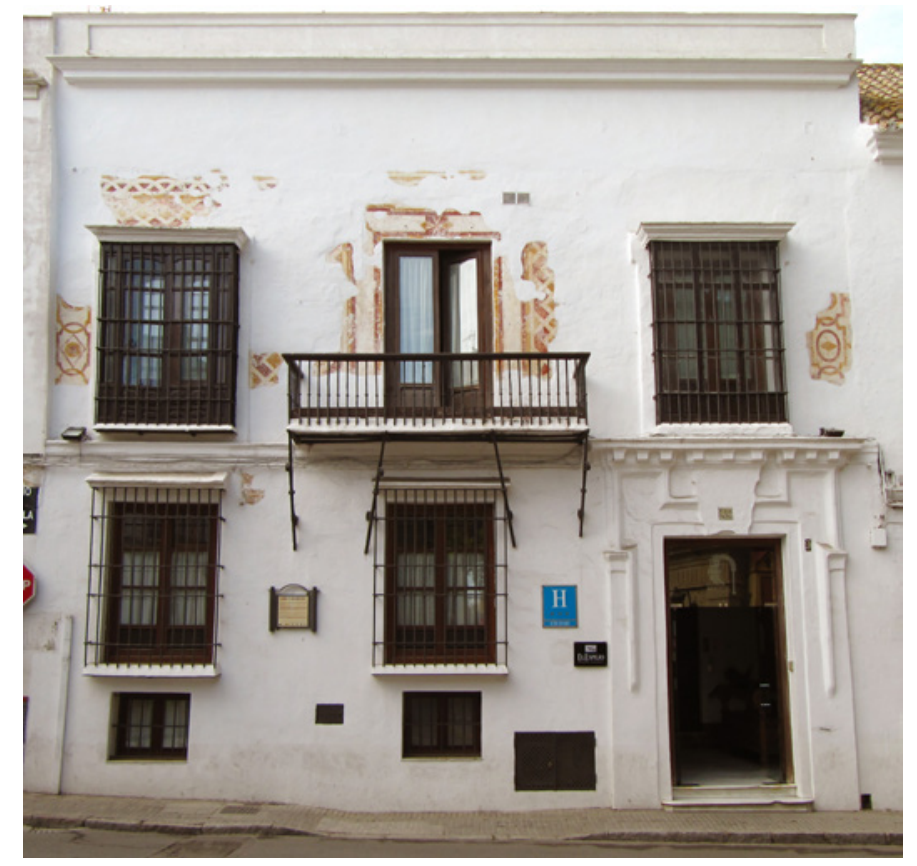

Figura 9. Casa en c/ Caballeros n 9 "Posada de Palacio". Ejemplo temprano de restauración de motivos de decoración externa. 


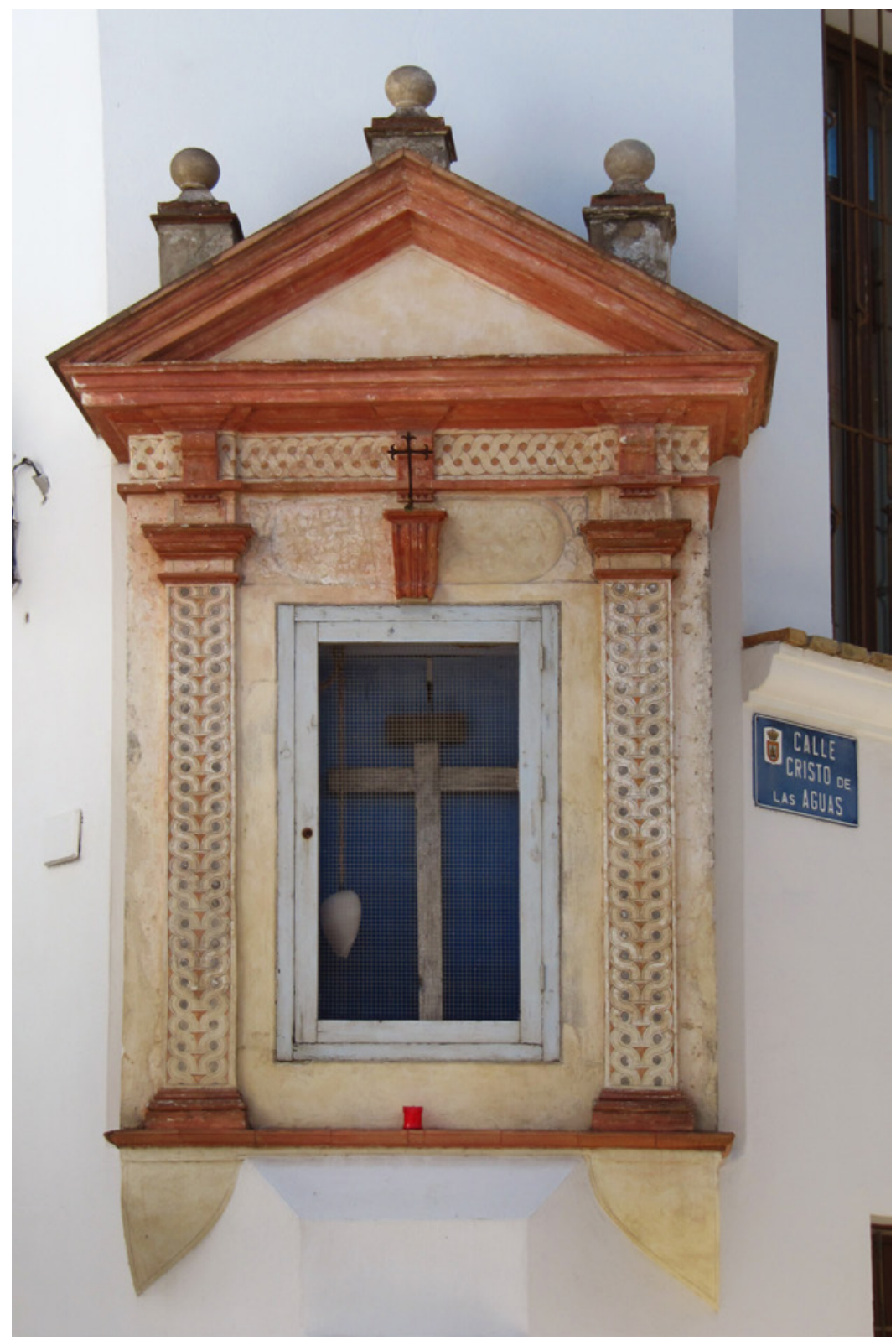

Figura 10. Capilla de la c/ Cristo de las Aguas. Pilastra y friso con eslabones entrelazados dobles. 